\title{
THE COVID-19 EFFECT ON SECURITY MORTGAGE VALUATION
}

\section{GIOVANNA DI LORENZO and MASSIMILIANO POLITANO}

Department of Economic and Statistical Sciences

University of Naples "Federico II"

Naples

Italy

e-mail: giodilor@unina.it

politano@unina.it

\begin{abstract}
The reverse mortgage market has been expanding rapidly in developed economies in recent years. Reverse mortgages provide an alternative source of funding for retirement income and health care costs. We often hear the phrase "house rich and cash poor" to refer the increasing number of elderly persons who hold a substantial proportion of their assets in home equity. Reverse mortgage contracts involve a range of risks from the insurer's perspective. When the outstanding balance exceeds the housing value before the loan is settled, the insurer suffers an exposure to crossover risk induced by three risk factors: interest rates, house prices, and mortality rates. In this context, Covid-19 has occurred and the insurer is faced with this additional source of 2020 Mathematics Subject Classification: 91B46.
\end{abstract}

Keywords and phrases: equity release products, reverse mortgage, CIR model, mortality curve, Covid-19.

Received March 31, 2021; Revised April 21, 2021

(ㄷ) 2021 Scientific Advances Publishers

This work is licensed under the Creative Commons Attribution International License (CC BY 3.0).

http://creativecommons.org/licenses/by/3.0/deed.en_US

Open Access (cc) (P)


risk. We analyse the combined impact of these risks on the pricing and the risk profile of reverse mortgage loans. We consider a CIR process for the evolution of the interest rate, a Black \& Scholes model for the dynamics of house prices and the Gompertz model for the trend in mortality Our results show that the decrease in the mortality curve due to Covid exposes the insurer to higher risks once the shock is reabsorbed. The risk is higher the higher the age of entry. Only a significant reduction of the shock adjustment coefficient will return the situation to normality.

\section{Introduction}

The trends of mortality improvement have shown, in recent years, that in many countries around the world life expectancy from birth is well over 80 years. Governments and industries have tried to decrease their financial burden by deferring the retirement age or reducing the benefit people receive. Research has found that retired people often have plenty of equity locked in their homes but very few liquid assets to rely on to support their daily needs. For this reason, we often hear the phrase "house rich and cash poor" to refer the increasing number of an elderly person who hold a substantial proportion of their assets in home equity. The financial industry tried to enter this market because of the fact reverse mortgages might provide a more practical solution.

Reverse mortgages are financial contracts that allow retirees to convert their home equities into either a lump sum or an annuity, but still maintain ownership and residence until they die, sell or vacate their home to live elsewhere. Loans made through a reverse mortgage accrue with interest and are settled only upon the death of the borrower, sale of the property or the vacation of its residents. There are no repayments made during the loan, and no assets other than the home may be attached to debt repayment. If, at time of settlement, the loan accrued with interest is larger than the sale price of the property, then the provider (or lender), usually a bank or an insurance company, recover only up to the sale price of the property.

In Italy, reverse mortgages, knows as PIV, were established in 2005 and then modified in 2015. 
The reverse mortgage products involve a range of risks from the provider's perspective. The outstanding balance usually accumulates at a faster rate than the appreciating rate of the housing value, therefore, if the outstanding balance exceeds the housing value before the loan is settled, the lender starts to incur in a loss. The crossover risk is crucial for managing revere mortgages effectively. It can be induced by three risk factors: interest rates, housing prices, and mortality rates. In this context, Covid-19 has led to a significant change in the mortality curve and added a further source of risk.

In this field, Wang et al. [14] proposed a securitization method to hedge longevity risk inherent in reverse mortgage products. In [7], using a three-dimensional lattice method, numerically calculate fair coupon rates for crossover bonds. Shao et al. [12] study the large idiosyncratic component in the house price risk. Tsay et al. [13] allow the house prices and interest rates to be stochastic with a deterministic distribution of termination time. Dowd et al. [5] outline the valuation process for a negative equity guarantee.

Furthermore, Covid has added a further uncertainty by causing a parallel shift in the death curve. For this reason, it is useful to read [2], [4], [8], [11], [15] which deals with the phenomenon of mortality in old age.

In this paper, referring to Italian case, we consider the effect of interest, mortality and stock prices dynamics in order to investigate the actuarial balance of the contract. We study the Covid effect on this balance by comparing the mortality scenarios of 2020 with the average of the previous 5 years.

The paper is organized as follows. Section 2 examines the reverse mortgage contract and present the stochastic model for interest rates, house prices, and the mortality curve law. In Section 3, we develop a framework to capture the stochastic dynamic of the contract. Section 4 illustrate the results. Section 5 concludes. 


\section{The Reverse Mortgage Contract}

An Italian reverse mortgage loan was modelled, using as an example a retired individual who takes out a reverse mortgage loan for a value $M_{0}$, against a house currently valued $I_{0}$. If, at time $t$, the loan amount is $M_{t}$ and the house price is $I_{t}$, then, by definition, the value of a reverse mortgage loan is

$$
Y_{t}=\min \left(M_{t}, I_{t}\right)
$$

In the put decomposition language, we can write that

$$
Y_{t}=M_{t}-\max \left(M_{t}-I_{t}, 0\right) .
$$

Therefore, entering a reverse mortgage contract, for the lender, is equivalent to taking out a loan without a real estate guarantee and buying a put option written on the value of the mortgaged property, with the random exercise price and random exercise time. In our case, by definition, the duration of the contract is equal to the remaining lifetime of the insured.

If the loan amount $M_{t}$ accumulates at a risk-free rate $i_{t}$, the house price $I_{t}$ appreciates at a rate $\delta_{t}$, then

$$
\begin{aligned}
M_{t} & =M_{0} \exp \left(\int_{0}^{\hat{S}} r_{t} d t\right), \\
I_{t} & =I_{0} \exp \left(\int_{0}^{\hat{S}} \delta_{t} d t\right), \\
Y_{t} & =\left[M_{0} \exp \left(\int_{0}^{\hat{S}} r_{t} d t\right), I_{0} \exp \left(\int_{0}^{\hat{S}} \delta_{t} d t\right)\right] \\
& =M_{0} \exp \left(\int_{0}^{\hat{S}} r_{t} d t\right)-\max \left[M_{0} \exp \left(\int_{0}^{\hat{S}} r_{t} d t\right)-I_{0} \exp \left(\int_{0}^{\hat{S}} \delta_{t} d t\right), 0\right],
\end{aligned}
$$

where $\tilde{S}$ is the remaining lifetime of the insured. Obviously, for practical purposes, it must be considered that only a certain percentage of the value of the property is granted. 
Now, at $t=0$, the net asset value of the operation is given by

$$
\begin{aligned}
N A V(0) & =V\left(0, M_{\widetilde{S}}\right)-V\left(0, \max \left\{M_{\widetilde{S}}-I_{\widetilde{S}}, 0\right\}\right)-\alpha I_{0} \\
& =\sum_{k=1}^{\omega} V\left(0, Y_{k}\right)_{k-1 / 1} q_{x}-\alpha I_{0},
\end{aligned}
$$

where

$$
Y_{k}=\left\{\begin{array}{cc}
\min \left(M_{k}, I_{k}\right) & w \cdot p_{\cdot k-1 / 1} q_{x} \\
0 & w \cdot p \cdot 1-_{k-1 / 1} q_{x}
\end{array}\right.
$$

With $\omega$ equal to the extreme age and ${ }_{k-1 / 1} q_{x}$ is the deferred probability of death. In the case of the put decomposition, we have

$$
\begin{aligned}
N A V(0) & =V\left(0, M_{\widetilde{S}}\right)-V\left(0, \max \left\{M_{\widetilde{S}}-I_{\widetilde{S}}, 0\right\}\right)-\alpha I_{0} \\
& =\sum_{k=1}^{\omega}\left(M_{k} v_{k}^{*}-p_{k}\right)_{k-1 / 1} q_{x}-\alpha I_{0},
\end{aligned}
$$

where

$$
\begin{aligned}
& M_{k}=\alpha I_{0} \exp \left(\int_{0}^{k} r_{t} d t\right), \\
& v *_{k}=\exp \left(-\int_{0}^{k} \mu_{t} d t\right), \\
& p_{k}=V\left(0, \max \left\{M_{k}-I_{k}, 0\right\}\right),
\end{aligned}
$$

with $\mu$ is the cost of capital rate. 


\section{Description of the Interest Rates, Housing Price and Mortality Models}

\subsection{Interest rate model}

The interest rate dynamics is described by means of the diffusion process

$$
d r_{t}=f^{r}\left(r_{t}, t\right) d t+l^{r}\left(r_{t}, t\right) d Z_{t}^{r}
$$

where $f^{r}\left(r_{t}, t\right)$ is the drift of the process, $l^{r}\left(r_{t}, t\right)$ is the diffusion process, and $Z_{t}^{r}$ is a standard Brownian motion. In particular, the Cox-Ingersoll and Ross model [3] the drift and diffusion coefficient are defined respectively as

$$
f^{r}\left(r_{t}, t\right)=k\left(\theta-r_{t}\right), \quad l^{r}\left(r_{t}, t\right)=\sigma_{r} \sqrt{r_{t}}
$$

where $k$ is the mean reverting coefficient, $\theta$ is the long-term period normal rate, and $\sigma_{r}$ is the spot rate volatility.

This time, interest rate date for the IRS 5-25 curves for the period 01/2001 - 12/2020 were considered. Figure 1 shows the result.

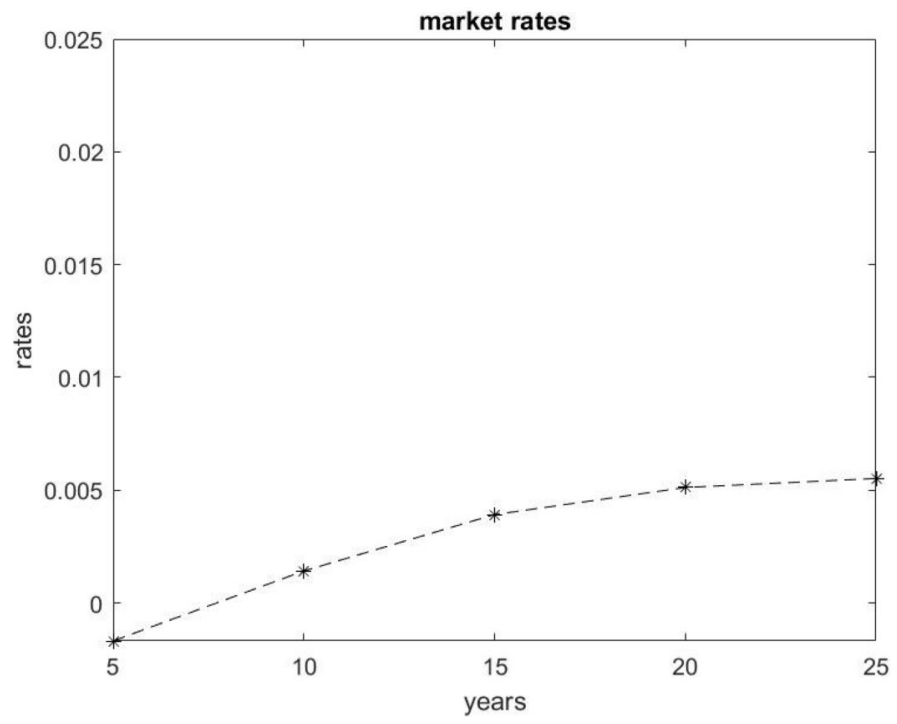

Figure 1. IRS curve 5-25 years. 
This graph is obtained using the MATLAB toolbox for Cox-IngersollRoss mean-reverting square root diffusion model.

\subsection{Housing price model}

Mortgage valuation typically rely the assumption that housing prices follow a stochastic geometric Brownian motion process. The diffusion process for this dynamic is given by the stochastic differential equation

$$
d S_{t}=f^{S}\left(S_{t}, t\right) d t+g^{S}\left(S_{t}, t\right) d Z_{t}^{S} .
$$

As a Black-Scholes type model [1] is assumed, one obtain

$$
f^{S}\left(S_{t}, t\right)=\mu_{S} S_{t}, \quad g^{S}\left(S_{t}, t\right)=\sigma_{S} S_{t} .
$$

In our case, the valuation of $p_{k}$ in (5) is given by

$$
p_{k}=V\left(0, \max \left\{M_{k}-I_{k}, 0\right\}\right)=\left[M_{n} e^{-r n} N\left(-d_{2}\right)-I_{n} e^{-q n} N\left(-d_{1}\right)\right],
$$

with

$$
d_{1}=\frac{\log \left[\frac{I_{n}}{M_{n}}\right]+\left(r-q+\sigma^{2} / 2\right)(T-t)}{\sigma \sqrt{T-t}}, \quad d_{2}=d_{1}-\sigma \sqrt{T-t} .
$$

For the valuation of the put option, we consider a free risk rate given by the IRS rate, a dividend rate of 0 , an annual volatility of the underlying of $10 \%$.

\subsection{Mortality model}

The natural mortality rate at chronological age $x$, in the Gompertz law of mortality [6], is expressed as

$$
\mu_{x}-\gamma=h e^{g x}
$$

where $h$ is a modal coefficient, $g$ is a dispersion coefficient, and $\gamma$ is an accidental death rate. In this context, with $\gamma=0$, the one-year death rate will be

$$
q_{x}=1-e^{h e^{g x}\left(1-e^{g}\right) / g} .
$$


So, while $\mu_{x}$ increases exponentially, the one-year death rate does not. The choice of the Gompertz model is justified by the fact that it is suitable for describing a parallel shock of the mortality curve [9]. We know that the Gompertz model works well over the range 60-90, but at higher age it usually overstates mortality rates [10]. However, we know that Covid affects the older ages so its choice is justified by this circumstance. Now, a parallel shock of the mortality curve is defined as the biologically ageing by $v / g$ years in a Gompertzian framework. In practice, in the pre-virus period we have

$$
\mu_{x}-\gamma=h e^{g x} .
$$

While, during the virus period we have

$$
\hat{\mu}_{x}-\hat{\gamma}=h e^{g\left(x+\frac{v}{g}\right)}
$$

During the week, ISTAT (Italian Statistical Institute), with the BES report, told us that life expectancy at birth was reduced in 2020 to 82.3 years. We then tried to modify the mortality force function (2015-2019 average) to achieve this result. We calculated the adjustment coefficient $v=0.756$ and we obtained the function in red assuming the deviation did not occur before reaching 60 years. 


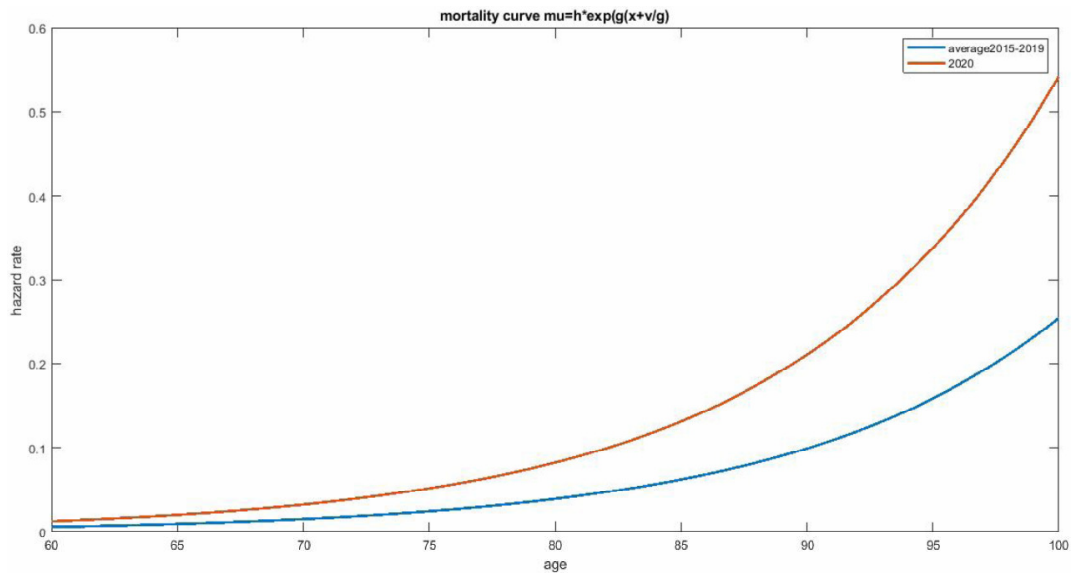

Figure 2. Mortality curve 2020 vs. average 2015-2019.

This graph is obtained using the MATLAB toolbox for generate life tables from calibrated Gompertz mortality model. It shows the shift in the 2020 mortality curve of 2020 compared to the 2015 -2019 average due to the Covid effect.

\section{Numerical Results}

The purpose of this application is to study the behaviour of the NAV, expressed by (5), and to investigate the behaviour of the interest rate risk and the mortality risk, including the effect of Covid on the mortality curve. They were considered:

- a borrower of initial age 60 and then gradually variable owner of a property worth 100,000,00 euros. Given the initial age, the residual life span is estimated using the Gompertz mortality model;

- the annual collection rate for the lender is given by the IRS rate estimated by the interest CIR model for the corresponding maturity;

- for the purpose of evaluating the put option, we consider a free risk rate given by the IRS rate, a dividend rate of 0 , an annual volatility of the underlying of $10 \%$. 
First of all we are interested in calculating the value of the discount rate that resets the NAV considering the average mortality 2015-2019. Once the rate has been found, we are interested in studying the average mortality profile in order to evaluate the effect on mortality for the period 2015-2019 and then for 2020. We studied this problem using age $x=65$ (retirement age in Italy) and age $x=80$ (extreme age of the loan).
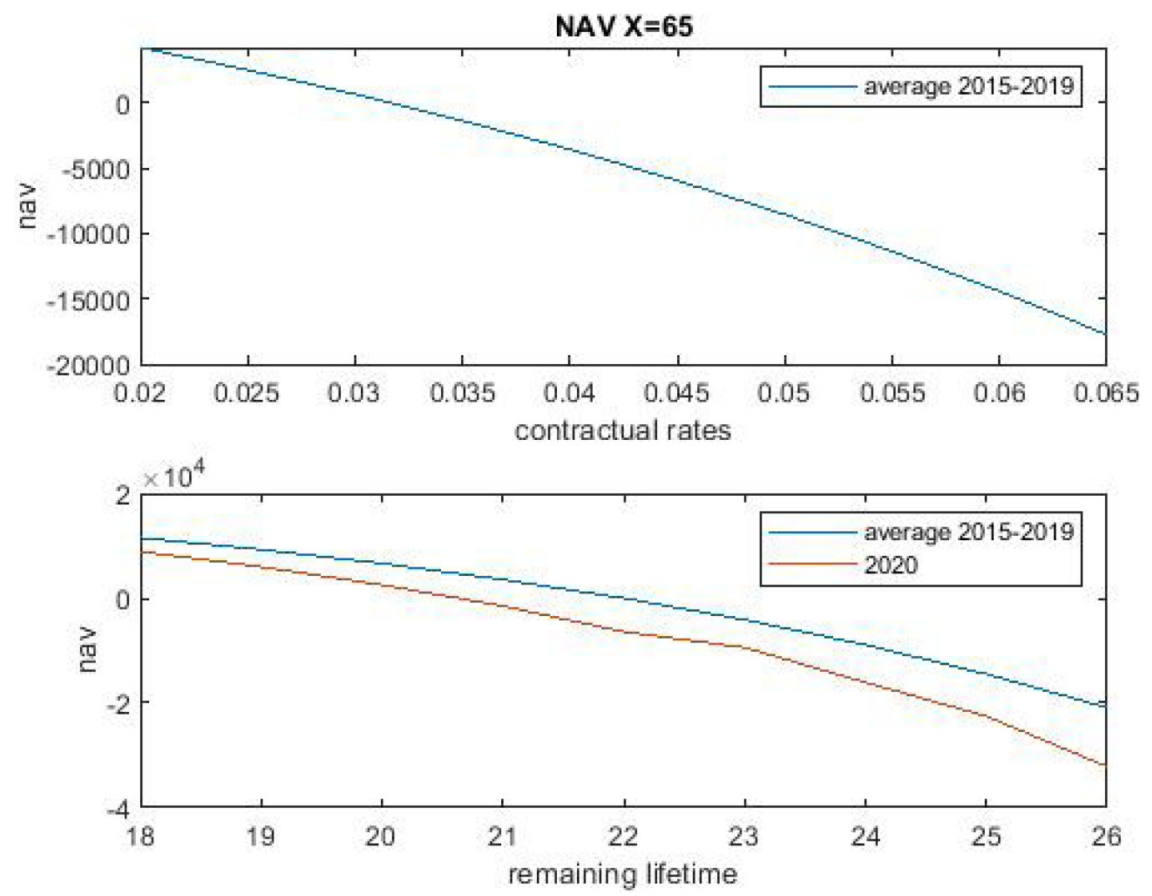

Figure 3. NAV as function of the contractual rate and residual lifetime fixed at 22 (first plot). NAV as function of the residual lifetime and contractual rate equal to $3.162 \%$ (second plot). Entry age $x=65, \alpha=25 \%$.

In the Figure 3 , the discount rate is 25 -year IRS rate while the percentage of financed value is $25 \%$. We can see that the rate that makes the NAV equal to 0 , is $3.162 \%$. For higher rates, the lender runs the request that mortgaged property does not cover the amount of the borrowed capital. The second plot studies the behaviour of the NAV as 
the residual life varies. In this case, the considered contractual rate is the one that makes the NAV equal to 0 . If we consider the average mortality 2015-2019, it can be noted that for life spans higher than 22 years, the lender runs the request that the mortgaged property does not cover the amount of the borrowed capital. If we consider the Covid shock of 2020, the value of 22 years becomes less than 21 years.
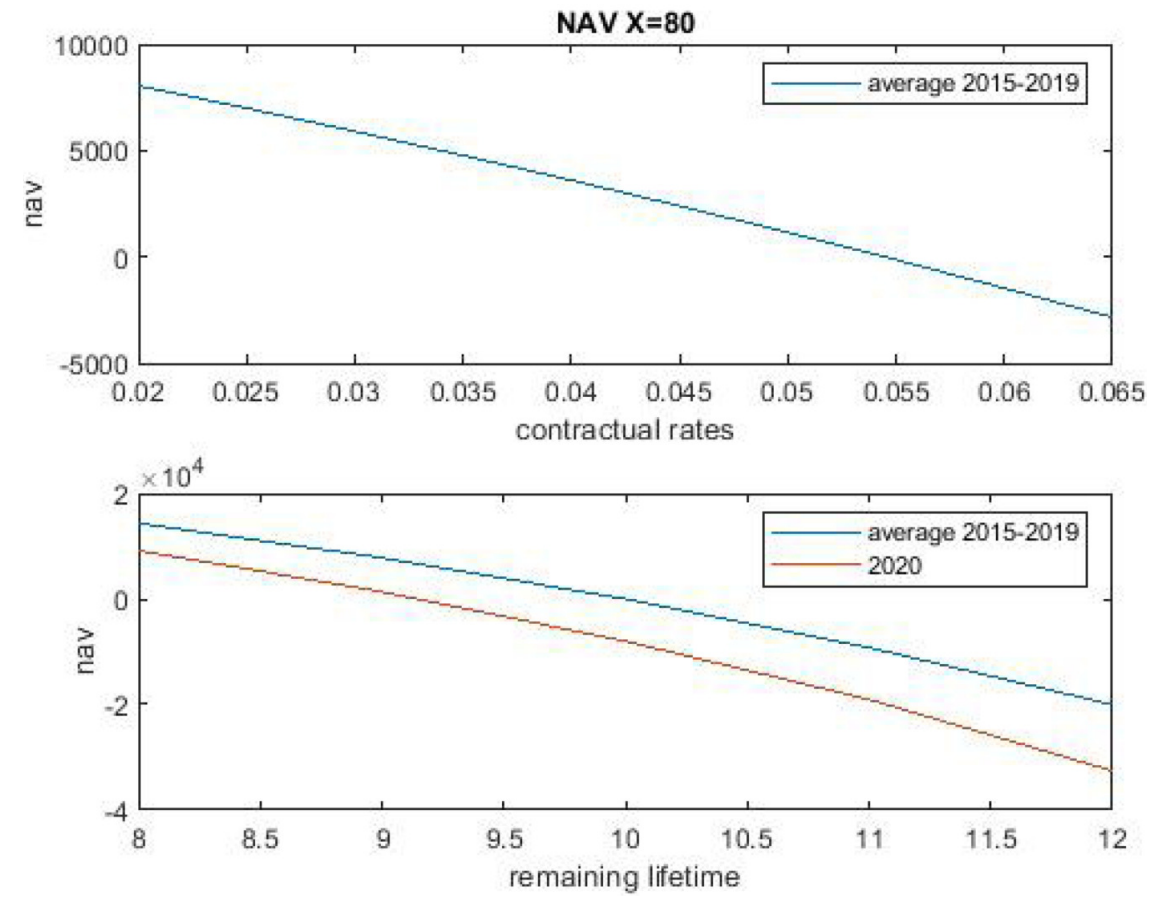

Figure 4. NAV as function of the contractual rate and residual lifetime fixed at 10 (first plot). NAV as function of the residual lifetime and contractual rate equal to $5.445 \%$ (second plot). Entry age $x=80, \alpha=40 \%$.

In the Figure 4, the logic is the same, that is to evaluate investment risk and mortality risk. Obviously, the percentage of the property value financing varies. The discounting rate varies too. The results show a trend similar to that discussed for $x=65$. As you can see, there is a 
reduction of almost 2 years (from 11 to 9 ) due to Covid. But in this case the effect is even greater because the residual life is shorter. This advises against selling this type of product to advanced ages.

\section{Conclusion}

Reverse mortgages are financial contracts that allow retirees to convert their home equities into either a lump sum or an annuity, but still maintain ownership and residence until they die, sell or vacate their home to live elsewhere. They involve a range of risks from the provider's perspective. In addition to interest risk, house price risk and mortality risk, Covid-19 has led to a significant change in the mortality curve and added a further source of risk. In this field, referring to Italian case, we consider the effect of interest, mortality and stock prices dynamics in order to investigate the actuarial balance of the contract. We have studied the Covid effect on this balance by comparing the mortality scenarios of 2020 with the average of the previous 5 years. Our results show the lender runs the request that the mortgaged property does not cover the amount of the borrowed capital. Moreover, if we consider the Covid shock of 2020, this risk becomes higher at higher ages. As you can see in Figure 5 , the shock of Covid is now extremely unlikely to last forever. It will most likely be reabsorbed in the next few years. This means that the calculated adjustment coefficient $v=0.756$ is bound to decrease. 


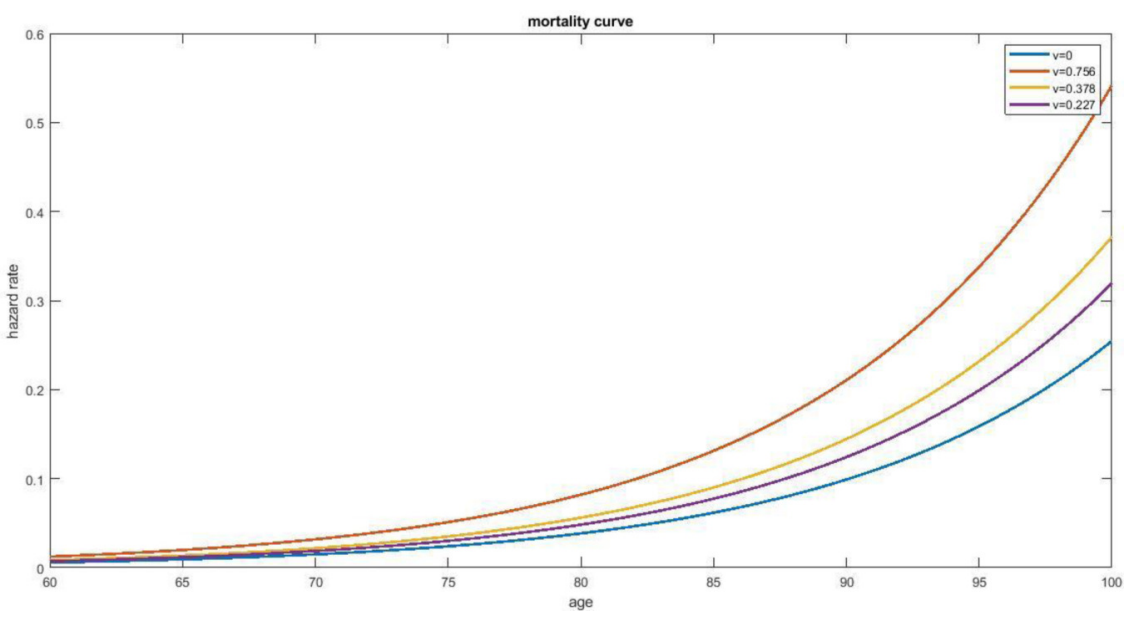

Figure 5. Mortality curve for different values of $v$.

For this reason, if we assume a reduction of $50 \%$ and $70 \%$ in the next year 2021 in the value of $v$, we can see how the curves can get closer. The longer Covid lasts, the longer it will take to absorb the shock.

\section{References}

[1] F. Black and M. Scholes, The pricing of options and corporate liabilities, Journal of Political Economy 81(3) (1973), 637-654.

[2] A. Case and A. Deaton, Mortality and morbidity in the 21st century, Brookings Papers on Economic Activity (2017), 397-476.

DOI: https://doi.org/10.1353/eca.2017.0005

[3] J. C. Cox, J. E. Ingersoll and S. A. Ross, A theory of the term structure of interest rates, Econometrica 53(2) (1985), 385-407.

DOI: https://doi.org/10.2307/1911242

[4] M. Dahl, Stochastic mortality in life insurance: Market reserves and mortalitylinked insurance contracts, Insurance: Mathematics and Economics 35 (2004), 113-136.

DOI: https://doi.org/10.1016/j.insmatheco.2004.05.003

[5] K. Dowd, D. Buckner, D. Balke and J. Fry, The valuation of no-negative equity guarantees and equity release mortgages, Economic Letters 184 (2019); Article 108669.

DOI: https://doi.org/10.1016/j.econlet.2019.108669 
[6] B. Gompertz, On the nature of the function expressive of the law of human mortality, and on a new mode of determining the value of life contingencies, Philosophical Transaction of the Royal Society of London 115 (1825), 513-583.

DOI: https://doi.org/10.1098/rstl.1825.0026

[7] H. C. Huang, C. W. Wang and Y. C. Miao, Securitization of crossover risk in reverse mortgages, The Geneva Papers on Risk and Insurance 36(4) (2011), 622-647.

DOI: https://doi.org/10.1057/gpp.2011.23

[8] M. A. Milevsky, Calibrating Gompertz in reverse: What is your longevity-riskadjusted global age?, Insurance: Mathematics and Economics 92 (2020), 147-161.

DOI: https://doi.org/10.1016/j.insmatheco.2020.03.009

[9] E. Pitacco, Survival models in a dynamic context: A survey, Insurance: Mathematics and Economics 35(2) (2004), 279-298.

DOI: https://doi.org/10.1016/j.insmatheco.2004.04.001

[10] S. J. Richards, A handbook of parametric survival models for actuarial use, Scandinavian Actuarial Journal 2012(4) (2012), 233-257.

DOI: https://doi.org/10.1080/03461238.2010.506688

[11] W. Ries and D. Pothig, Chronological and biological age, Experimental Gerontology 19(3) (1984), 211-216.

DOI: https://doi.org/10.1016/0531-5565(84)90041-X

[12] A. W. Shao, K. Hanewald and M. Sherris, Reverse mortgage pricing and risk analysis allowing for idiosyncratic house price risk and longevity risk, Insurance: Mathematics and Economics 63 (2015), 76-90.

DOI: https://doi.org/10.1016/j.insmatheco.2015.03.026

[13] J. T. Tsay, C. C. Lin, L. J. Prather and R. J. Buttimer, An approximation approach for valuing reverse mortgages, Journal of Housing Economics 25 (2014), 39-52.

DOI: https://doi.org/10.1016/j.jhe.2014.03.001

[14] L. Wang, E. A. Valdez and J. Piggot, Securitization of longevity risk in reverse mortgages, North American Actuarial Journal 12(4) (2008), 345-371.

DOI: https://doi.org/10.1080/10920277.2008.10597529

[15] W. J. Willemse and R. Kaas, Rational reconstruction of frailty-based mortality models by a generalisation of Gompertz' law of mortality, Insurance: Mathematics and Economics 40(3) (2007), 468-484.

DOI: https://doi.org/10.1016/j.insmatheco.2006.07.003 